\title{
Erratum to: Bacterial and Protozoan Lipoxygenases Could be Involved in Cell-to-Cell Signaling and Immune Response Suppression
}

\author{
G. F. Kurakin ${ }^{1, a *}$, A. M. Samoukina ${ }^{2}$, and N. A. Potapova ${ }^{3,4}$ \\ ${ }^{1}$ Department of Biochemistry and Laboratory Medicine, Tver State Medical University, \\ Ministry of Health of the Russian Federation, 170100 Tver, Russia \\ ${ }^{2}$ Department of Microbiology, Virology, and Immunology, Tver State Medical University, \\ Ministry of Health of the Russian Federation, 170100 Tver, Russia \\ ${ }^{3}$ Kharkevich Institute for Information Transmission Problems, Russian Academy of Sciences, 127051 Moscow, Russia \\ ${ }^{4}$ Faculty of Bioengineering and Bioinformatics, Lomonosov Moscow State University, 119234 Moscow, Russia \\ ${ }^{a}$ e-mail: kurackin-georgy@yandex.ru \\ Received June 19, 2020 \\ Revised June 22, 2020 \\ Accepted June 22, 2020
}

DOI: $10.1134 / \mathrm{S} 0006297920100168$

The original article can be found online at https://doi.org/10.1134/S0006297920090059

On p. 1051, Fig. 2, legend: instead of "nor" should read "not".

On p. 1053, Fig. 4, legend: instead of "initial" should read "original".

On p. 1059, Fig. 7, legend: instead of "initial" should read "original". 